\title{
Cultivo inicial de mangabeira consorciada com adubos verdes no cerrado do sudeste de Goiás
}

A Mangabeira (Hancornia speciosa Gomes) ocorre principalmente nos Biomas Cerrado e Caatinga. O fruto da mangabeira é o principal produto explorado pela frutífera principalmente por indústrias de polpas, sucos e sorvetes. O uso de leguminosas para contribuir no fornecimento de nitrogênio para as culturas, ajudando no estabelecimento das mudas no campo. O objetivo deste estudo foi avaliar o desenvolvimento inicial da cultura da Mangabeira, consorciado com adubos verdes A pesquisa foi conduzida no campo experimental da Universidade Estadual de Goiás, Câmpus Ipameri, situada a 170 46' 30,3" latitude Sul, 48ㅇ 19' 15,6" de longitude Oeste e altitude de aproximadamente 800 metros. Mudas de $\mathrm{H}$. speciosa com 11 meses de idade, foram plantadas no campo com espaçamento de $8 \times 5$. Entre as linhas foram semeadas as crotalaria juncea, mucuna preta, feijão-guandu (Cajanus cajan) e feijão de porco (Canavalia ensiformis), em espaçamento $0,40 \times 0,80$. As variáveis analisadas foram: altura da planta em centímetros $(\mathrm{cm})$; diâmetro do caule $(\mathrm{mm})$; diâmetro de copa $(\mathrm{cm})$. Os dados foram submetidos à análise de variância e, nos casos em que o teste $\mathrm{F}$ foi significativo, realizou-se o teste de Scott-Knott para comparação múltipla das médias dos tratamentos principais. 0 incremento de altura final da mangabeira foi favorecido pelo feijão guandu. O consórcio com feijão de porco proporcionou maior incremento final de diâmetro do caule. O plantio de mudas de mangabeira (Hancornia speciosa) em consórcio com adubação verde se apresenta como promissor.

\section{Initial cultivation of mangabeira consorced with green fertilizers in the closed southeast of Goiás}

\begin{abstract}
Mangabeira (Hancornia speciosa Gomes) occurs mainly in the Savannah and Caatinga Biomes. The fruit is the main product exploited by the fruit mainly by pulp juice and ice cream industries. The use of legumes to contribute in the supply of nitrogen to the crops, helping in the establishment of seedlings in the field. The objective of this study was to evaluate the initial development of the $\mathrm{H}$. speciosa crop, intercropped with green manures. The research was conducted in the experimental field of the State University of Goiás, Câmpus Ipameri, located at 170 46 ' 30,3' 'South latitude, 48 19' 15,6 " West longitude and altitude of approximately 800 meters. Seedlings of $\mathrm{H}$. speciosa with 11 months of age were planted in the field with spacing of $8 \times 5$. Among the lindas were crotalaria juncea, mucuna black, guindu beans (Cajanus cajan) and pork beans (Canavalia ensiformis), in a spacing of $0.40 \times 0.80$. The variables analyzed were: plant height in centimeters $(\mathrm{cm})$; Stem diameter $(\mathrm{mm})$; Cup diameter $(\mathrm{cm})$. The data were submitted to analysis of variance and, in cases where the $\mathrm{F}$ test was significant, the Scott-Knott test was performed for multiple comparison of means of the main treatments. The final height increment of the mangabeira was favored by pigeon pea. The consortium with pigs' beans provided the largest final increase in stem diameter. The planting of $\mathrm{H}$. speciosa seedlings in a consortium with green manure presents as promising.
\end{abstract}

Keywords: Native Fruits; Apocinaceae; Leguminous.

Topic: Conservação da Biodiversidade

Reviewed anonymously in the process of blind peer.
Received: $12 / 02 / 2019$

Approved: 28/03/2019
Roberli Ribeiro Guimarães (iD)

Universidade Estadual de Goiás, Brasil

http://lattes.cnpq.br/7356969522499417

http://orcid.org/0000-0002-9283-0233

roberligeo@gmail.com

Muza do Carmo Vieira

Universidade Estadual de Goiás, Brasil

http://lattes.cnpq.br/7356969522499417

http://orcid.org/0000-0003-1730-9541

mcvmuza@gmail.com

Ednaldo Cândido Rocha (iv)

Universidade Estadual de Goiás, Brasil

http://lattes.cnpq.br/9200178886364293

http://orcid.org/0000-0002-2554-777X

ednaldorocha@yahoo.com.br

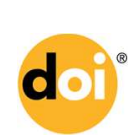

DOI: 10.6008/CBPC2179-6858.2019.002.0007

\author{
Nei Peixoto (iD \\ Universidade Estadual de Goiás, Brasil \\ http://lattes.cnpq.br/35375666859013207 \\ http://orcid.org/0000-0003-2319-8139 \\ nei.peixoto48@gmail.com \\ Briza i Volusia Schetin \\ Universidade Estadual de Goiás, Brasil \\ brizavolusia@gmail.com \\ Larissa Leandro Pires (D) \\ Universidade Estadual de Goiás, Brasil \\ http://lattes.cnpq.br/4811315528353849 \\ http://orcid.org/0000-0001-9373-3868 \\ larissapires.ufg@gmail.com
}

\section{Referencing this:}

GUIMARÃES, R. R.; VIEIRA, M. C.; ROCHA, E. C.; PEIXOTO, N.; SCHETIN, B. V.; PIRES, L. L.. Cultivo inicial de mangabeira consorciada com adubos verdes no cerrado do sudeste de Goiás. Revista Ibero Americana de Ciências Ambientais, v.10, n.2, p.65-73, 2019. DOI: http://doi.org/10.6008/CBPC2179-6858.2019.002.0007 


\section{INTRODUÇÃO}

O Cerrado é considerado o segundo maior bioma do país ocupando $24 \%$ do território nacional, contando com uma diversidade de plantas e animais e povos que utilizam seus recursos naturais. Conta com alguns tipos mais comuns de vegetação, como: campo limpo, campo sujo, cerrado típico, cerradão, mata ciliar e vereda (LIMA, 2010).

A Mangabeira (Hancornia speciosa Gomes) ocorre principalmente nos Biomas Cerrado e Caatinga. É uma planta frutífera pertencente à família das apocináceas que pode atingir até 10 metros de altura. Esta planta é produtora de látex e casca com propriedades adstringentes. Este garante sua utilização na medicina popular $O$ fruto da mangabeira é o principal produto explorado pela frutífera principalmente por indústrias de polpas, sucos e sorvetes (SILVA JÚNIOR, 2004).

Vegeta espontaneamente em diversas regiões do país por ser uma planta nativa do Brasil, sendo mais abundante nas baixadas litorâneas do Nordeste e áreas de Cerrado. Em biomas que ocorrem naturalmente vem sofrendo elevadas agressões antrópicas e redução em suas populações nativas (LEDERMAN et al., 2000). A especulação imobiliária e implantação de coqueirais e canaviais como monocultura no litoral são as principais causas da diminuição da vegetação nativa e do número de mangabeiras (NETO et al., 2002).

A exploração desta frutífera ainda é extrativista e sem a existência de plantios racionais e tecnificados, ocasionando grande barreira para o aproveitamento de suas potencialidades (VIEIRA NETO, 1993) e recursos do solo. O extrativismo da mangabeira é realizado através da catação de frutos caídos ou pendentes na planta, em seguida são colocados em baldes e levados para o local de lavagem (MACÊDO, 2011).

Para o melhor aproveitamento dos recursos do solo, uma alternativa são os plantios consorciados (MAFRA et al., 2008), podendo destacar o uso de leguminosas para contribuir no fornecimento de nitrogênio para as culturas. Podem ser utilizadas antes ou depois da cultura principal, em plantio conjunto da cultura e o adubo verde escolhido e plantio na reta final do ciclo da cultura (EMBRAPA, 2011). Nesse sentido é necessária estratégias visando o desenvolvimento de mudas em campo para a conservação e manutenção de germoplasma para proteção de patrimônio genético. O objetivo deste estudo foi avaliar o desenvolvimento inicial de mudas de Mangabeira em cultivo com adubos verdes.

\section{MATERIAIS E MÉTODOS}

A pesquisa foi conduzida no campo experimental da Universidade Estadual de Goiás, Campus Ipameri, situada a 17은 46, 30," latitude Sul, 48 19' 15,6" de longitude Oeste e altitude de aproximadamente 800 metros. O clima de Ipameri é classificado como Aw, Tropical com estação seca no inverno, segundo Köppen. A temperatura média anual é de 250 C, com umidade relativa do ar variando de $58 \%$ a $81 \%$ e precipitação pluviométrica anual de $1.750 \mathrm{~mm}$, sendo que cerca de $80 \%$ das chuvas ocorrem nos meses de 
dezembro, janeiro, fevereiro e março e o restante se distribui, principalmente, nos meses de outubro e novembro.

O solo da área experimental é um Latossolo Vermelho - Amarelo Distrófico (EMBRAPA, 2006), textura areno-argilosa com as seguintes características químicas na camada de $0-20 \mathrm{~cm}: \mathrm{pH}=4,6 ; \mathrm{P}=12,9 \mathrm{mg} \cdot \mathrm{dm}^{-3}$, $\mathrm{K}=0,26 \mathrm{Cmolc} \cdot \mathrm{dm}^{-3} ; \mathrm{Al}=0,60 \mathrm{Cmolc} \cdot \mathrm{dm}-3 ; \mathrm{Ca}=1,13 \mathrm{Cmolc} \cdot \mathrm{dm}^{-3} ; \mathrm{Mg}=0,34 \mathrm{Cmolc} \cdot \mathrm{dm}^{-3} ; \mathrm{H}+\mathrm{Al}=3,3$ Cmolc. $\mathrm{dm}^{-3} ; \mathrm{CTC}=4,74 \mathrm{Cmolc} \cdot \mathrm{dm}^{-3} ; \mathrm{V}=41,27 \% ; \mathrm{MO}=2,1 \mathrm{~g} \cdot \mathrm{kg}$.

A área experimental possuía Brachiaria decumbens Stapf. Prain. em superfície. Em novembro de 2013, para a implantação do experimento foi realizado o dessecamento da vegetação utilizando Glyphosate $\left(4 \mid\right.$ ha $\left.^{-1}\right)$. Após 15 dias, mudas de H. speciosa, com 11 meses de idade, originadas de semeadura em sacos plásticos de $20 \times 30 \mathrm{~cm}$ e em substrato de terra de barranco + esterco curtido + , foram plantadas com espaçamento de 8 metros entre linhas e 5 metros entre plantas. Entre as linhas e 15 dias após o plantio da frutífera, foi realizada a abertura dos sulcos espaçados a $0,40 \mathrm{~m}$ para semeadura dos adubos verdes com auxílio de um subsolador. A semeadura das leguminosas, crotalaria juncea, mucuna preta, feijão-guandu (Cajanus cajan) e feijão de porco Canavalia ensiformis) foi realizada, manualmente, atentando-se para o espaçamento recomendado para as espécies cultivadas, variando entre 0,40 e 0,80 metros entre fileiras, segundo recomendações de Carvalho et al. (2006). Os adubos verdes foram incorporados quando apresentaram $50 \%$ de floração e a vegetação espontânea, antes da produção de sementes. A crotalaria, mucuna e feijão de porco, foram incorporadas aos 90 dias após a semeadura (DAS); o feijão - guandu aos 120 DAS. Não se utilizou adubo químico e corretivo no preparo do solo.

Utilizou-se o delineamento em blocos casualizados, em esquema de parcelas subdivididas. Os tratamentos principais foram os quatro espécies de adubos verdes e a vegetação espontânea utilizados e os tratamentos secundários foram as 9 épocas de avaliação das mudas, sempre a cada 60 dias, se estendendo até aos 540 dias após o plantio e semeadura.

A parcela experimental constituiu-se de três linhas, com três plantas e mangabeira, totalizando 9 plantas por parcela com quatro repetições. Considerou-se para a avaliação as plantas da linha central da parcela, sendo as plantas das linhas laterais, as bordaduras. As variáveis analisadas foram: altura da planta em centímetros $(\mathrm{cm})$; diâmetro do caule $(\mathrm{mm})$; diâmetro de copa $(\mathrm{cm})$. Para a medição da altura, os dados foram obtidos mediante a utilização de uma trena milimétrica de $100 \mathrm{~cm}$; o diâmetro $(\mathrm{mm})$ foi aferido a 5 $\mathrm{cm}$ do solo com o auxílio do paquímetro digital da marca Mitutoyo. Para o diâmetro da copa, utilizou-se uma trena milimetrada, obedecendo o critério do sentido Norte-Sul. Conforme a necessidade foram realizados os tratos culturais de manejo.

Os dados foram submetidos à análise de variância e, nos casos em que o teste $F$ foi significativo, realizou-se o teste de Scott-Knott para comparação múltipla das médias dos tratamentos principais. Adicionalmente, procedeu-se à análise de regressão linear ou polinomial para avaliar os tratamentos secundários (tempo). Foi necessário aplicar uma transformação quadrática aos dados (raiz de x+1 e raiz de x+2 para diâmetro da copa) para atender aos pressupostos metodológicos de normalidade de homogeneidade de variâncias, mas os resultados foram apresentados acompanhados das médias 
verdadeiras dos tratamentos para facilitar a interpretação dos dados. As análises estatísticas foram conduzidas utilizando o software SISVAR 5.3 (FERREIRA, 2008).

\section{RESULTADOS}

A altura das plantas de mangabeira apresentaram interação significativa com os adubos verdes utilizados ao longo dos meses de avaliação. Nas avaliações realizadas até 300 dias, não foi observado diferença significativa de incremento de altura com os adubos feijão guandu, feijão de porco, mucuna e vegetação espontânea, sendo esses tratamentos os que apresentaram maiores médias. Após 420 dias, estes adubos apresentaram diferença significativa e o feijão guandu apresentou a maior média de incremento diferindo dos demais, indicando que este adubo influenciou na altura final da frutífera (Tabela 1).

Tabela 1: Média dos valores para incremento em altura $(\mathrm{cm})$ de mudas de mangabeira (Hancornia speciosa) em desenvolvimento inicial em campo, consorciadas com diferentes tipos de adubação verde (Crotalária juncea; Feijão guandu, Feijão de porco, Vegetação espontânea), e épocas (dias) de avaliação. Ipameri/GO, 2016.

\begin{tabular}{|l|l|l|l|l|l|l|l|l|l|l|}
\hline \multirow{2}{*}{ Adubo Verde } & \multicolumn{7}{|l|}{ Incremento Médio De Altura (Cm) Acumulado Após O Plantio (Dias) } & \multirow{2}{*}{ Médias } \\
\cline { 2 - 14 } & $\mathbf{6 0}$ & $\mathbf{1 2 0}$ & $\mathbf{1 8 0}$ & $\mathbf{2 4 0}$ & $\mathbf{3 0 0}$ & $\mathbf{3 6 0}$ & $\mathbf{4 2 0}$ & $\mathbf{4 8 0}$ & $\mathbf{5 4 0}$ & \\
\hline Crotalária & $0,00 \mathrm{~b}$ & $0,25 \mathrm{~b}$ & $1,00 \mathrm{a}$ & $1,25 \mathrm{~b}$ & $1,50 \mathrm{~b}$ & $3,25 \mathrm{~b}$ & $6,25 \mathrm{c}$ & $9,50 \mathrm{~b}$ & $11,75 \mathrm{c}$ & 3,86 \\
\hline Feijão guan. & $1,00 \mathrm{a}$ & $1,50 \mathrm{a}$ & $2,00 \mathrm{a}$ & $3,00 \mathrm{a}$ & $3,50 \mathrm{a}$ & $\mathbf{4}, 75 \mathrm{a}$ & $10,25 \mathrm{a}$ & $14,25 \mathrm{a}$ & $18,00 \mathrm{a}$ & 6,47 \\
\hline Feijão porc. & $0,75 \mathrm{a}$ & $1,00 \mathrm{a}$ & $2,00 \mathrm{a}$ & $2,75 \mathrm{a}$ & $3,75 \mathrm{a}$ & $4,75 \mathrm{a}$ & $7,75 \mathrm{~b}$ & $10,50 \mathrm{~b}$ & $14,00 \mathrm{~b}$ & 5,25 \\
\hline Mucuna & $1,00 \mathrm{a}$ & $1,00 \mathrm{a}$ & $2,00 \mathrm{a}$ & $2,75 \mathrm{a}$ & $4,00 \mathrm{a}$ & $4,50 \mathrm{a}$ & $7,75 \mathrm{~b}$ & $10,50 \mathrm{~b}$ & $14,00 \mathrm{~b}$ & 5,28 \\
\hline Veg. Espon. & $0,50 \mathrm{a}$ & $1,00 \mathrm{a}$ & $1,75 \mathrm{a}$ & $2,75 \mathrm{a}$ & $3,50 \mathrm{a}$ & $3,75 \mathrm{~b}$ & $4,75 \mathrm{~d}$ & $7,00 \mathrm{c}$ & $8,75 \mathrm{~d}$ & 3,75 \\
\hline
\end{tabular}

Após 180 dias foram constatadas diferenças com o feijão de porco e a mucuna com as maiores médias de incremento com 0,38 e 0,42 respectivamente, porém sem diferença significativa entre os dois adubos. Após 360 dias, as variáveis para o feijão de porco se diferiram de todos os outros tratamentos com as maiores médias de incremento de diâmetro $(\mathrm{cm})$ até o fim das avaliações (Figura 1).

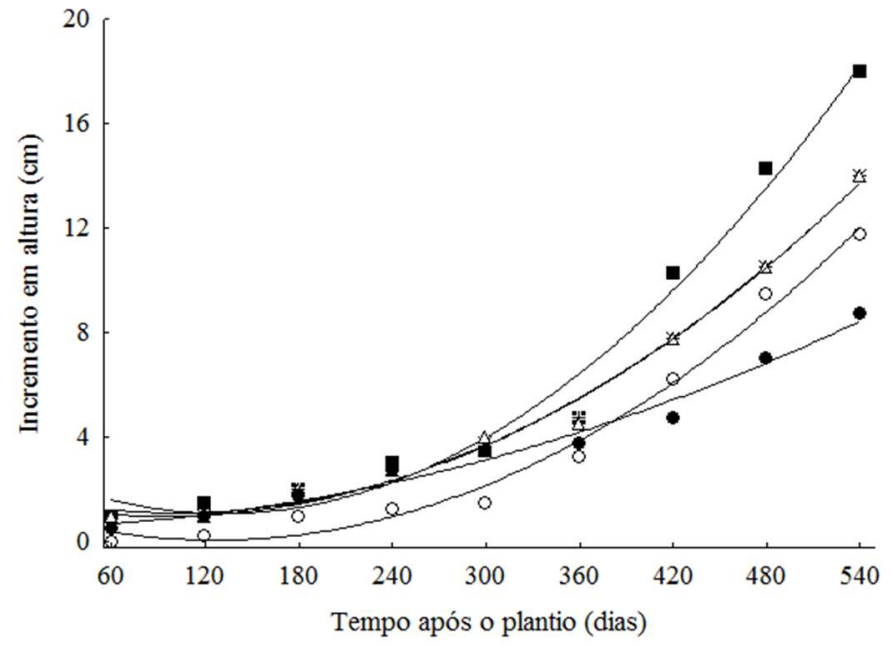

\footnotetext{
Legendas e equações de regressão ajustadas:
Q. Crotalaria $\left(\mathrm{y}=1,208333-0,017746 \mathrm{x}+0,00007 \mathrm{x}^{2} ; \mathrm{R}^{2}=0,985^{* *}\right)$

Eeijão guandu $\left(y=2,892857-0,027195 x+0,000103 x^{2} ; R^{2}=0,982 * *\right)$

米. Feijão de porco $\left(y=1,559524-0,012031 \mathrm{x}+0,000064 \mathrm{x}^{2} ; \mathrm{R}^{2}=0,993 * *\right)$

$\triangle$ Mucuna $\left(\mathrm{y}=1,815476-0,013506+0,000066 \mathrm{x}^{2} ; \mathrm{R}^{2}=0,99 * *\right)$

- Veg. espontânea $\left(\mathrm{y}=0,553571+0,001230 \mathrm{x}+0,000025 \mathrm{x}^{2} ; \mathrm{R}^{2}=0,979 * *\right)$
}

Figura 1: Análise de regressão para a altura das mudas de Hancornia speciosa $(\mathrm{cm})$ em diferentes épocas (dias) de avaliação e tipos de adubação verde. Ipameri/GO, 2018. 
Ao se observar a época de plantio e do tempo entre a semeadura e o corte da crotalária, feijão de porco, mucuna e feijão guandu, o benefício de aporte nutricional, para o sistema pode ter sido diferente, já que as três primeiras leguminosas, foram incorporadas aos 90 DAS, enquanto que o feijão guandu foi aos 120 DAS. Os tratamentos utilizados não apresentaram diferença nas observações de incremento médio de diâmetro de caule nas avaliações de 60 e 120 dias (Tabela 2).

Tabela 2: Média dos valores para incremento em diâmetro de caule $(\mathrm{cm})$ de mudas de mangabeira, (Hancornia speciosa) em desenvolvimento inicial em campo, consorciadas com diferentes tipos adubação verde (Crotalária juncea; Feijão guandu, Feijão de porco, Vegetação espontânea) e épocas (dias) de avaliação. Ipameri/GO, 2016.

\begin{tabular}{|c|c|c|c|c|c|c|c|c|c|c|}
\hline \multirow[t]{2}{*}{ Adubo Verde } & \multicolumn{9}{|c|}{ Incremento Médio De Diâmetro (Cm) Acumulado Após O Plantio (Dias) } & \multirow[t]{2}{*}{ Médias } \\
\hline & 60 & 120 & 180 & 240 & 300 & 360 & 420 & 480 & 540 & \\
\hline Crotalária & 0,10 a & 0,17 a & $0,17 \mathrm{~b}$ & 0,34 a & $0,42 \mathrm{a}$ & $0,55 \mathrm{~b}$ & $0,87 \mathrm{c}$ & $0,98 \mathrm{c}$ & $1,37 \mathrm{c}$ & 0,55 \\
\hline Feijão-guan. & $0,09 \mathrm{a}$ & $0,13 \mathrm{a}$ & $0,20 \mathrm{~b}$ & $0,38 \mathrm{a}$ & $0,51 \mathrm{a}$ & $0,61 b$ & $0,87 \mathrm{c}$ & $1,18 \mathrm{c}$ & $1,47 \mathrm{c}$ & 0,60 \\
\hline Feijão porc. & $0,16 \mathrm{a}$ & $0,18 \mathrm{a}$ & $0,38 \mathrm{a}$ & 0,49 a & $0,68 \mathrm{a}$ & $0,93 \mathrm{a}$ & $1,41 \mathrm{a}$ & $1,86 \mathrm{a}$ & $2,40 \mathrm{a}$ & 0,94 \\
\hline Mucuna & 0,19 a & $0,31 \mathrm{a}$ & 0,42 a & $0,53 a$ & $0,60 \mathrm{a}$ & $0,71 b$ & $1,14 b$ & $1,42 b$ & $1,87 b$ & 0,80 \\
\hline Veg. Espon. & 0,05 a & 0,12 a & $0,25 b$ & $0,40 \mathrm{a}$ & $0,50 a$ & $0,54 b$ & $0,70 \mathrm{c}$ & $1,05 \mathrm{c}$ & $1,29 \mathrm{c}$ & 0,54 \\
\hline
\end{tabular}

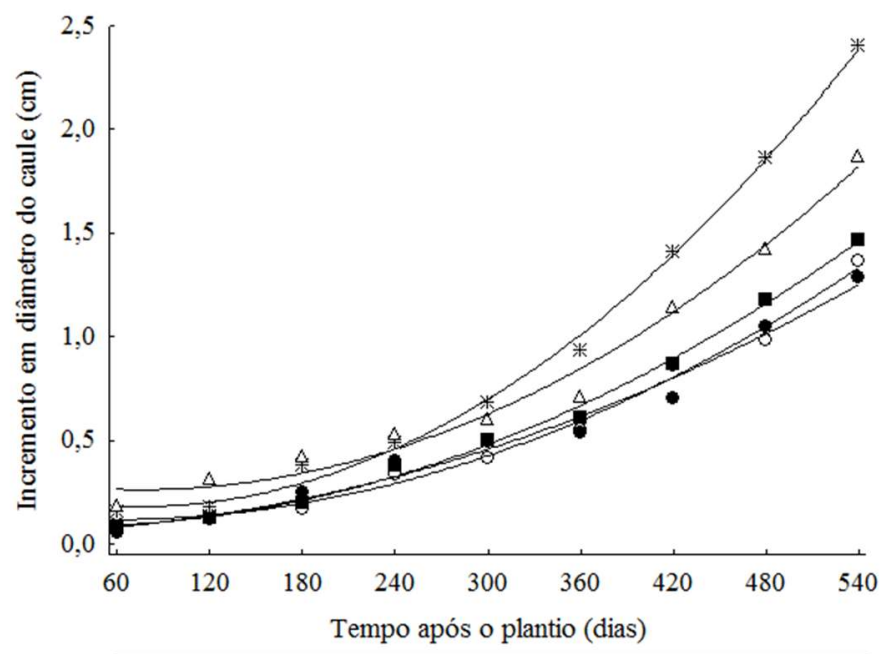

$$
\begin{gathered}
\text { Legandas e equações de regressão ajustadas: } \\
\text { Q. Crotalaria }\left(y=0,134881-0,000593 \mathrm{x}+0,000005 \mathrm{x}^{2} ; \mathrm{R}^{2}=0,99 * *\right) \\
\text { - Feijão guandu }\left(\mathrm{y}=0,087679-0,000244 \mathrm{x}+0,000005 \mathrm{x}^{2} ; \mathrm{R}^{2}=0,995^{* *}\right) \\
\text { *. Feijão de porco }\left(\mathrm{y}=0,238512-0,001527 \mathrm{x}+0,00001 \mathrm{x}^{2} ; \mathrm{R}^{2}=0,997 * *\right) \\
\triangle \text { Mucuna }\left(\mathrm{y}=0,303750-0,001088 \mathrm{x}+0,000007 \mathrm{x}^{2} ; \mathrm{R}^{2}=0,983^{* *}\right) \\
\text { - Veg. espontânea }\left(\mathrm{y}=0,055417+0,000243 \mathrm{x}+0,000004 \mathrm{x}^{2} ; \mathrm{R}^{2}=0,979 *\right)
\end{gathered}
$$

Figura 2: Análise de regressão para o diâmetro do caule de mudas de mangabeira (Hancornia speciosa) (cm) em diferentes épocas (dias) de avaliação e tipos de adubação verde. Ipameri/GO, 2018.

Não foram observadas diferenças estatísticas entre os adubos verdes utilizados e a vegetação espontânea para o incremento médio de copa $(\mathrm{cm})$ acumulado após o plantio (Tabela 3 e Figura 3).

Tabela 3: Média dos valores para incremento de diâmetro de copa (cm) de mudas de mangabeira (Hancornia speciosa) em desenvolvimento inicial em campo, consorciadas com diferentes tipos de adubação verde (Crotalária juncea; Feijão guandu, Feijão de porco, Vegetação espontânea) e épocas (dias) de avaliação Ipameri/GO, 2018.

\begin{tabular}{|l|l|l|l|l|l|l|l|l|l|l|}
\hline \multirow{2}{*}{ Adubo Verde } & \multicolumn{7}{|l}{ Incremento Médio De Copa (Cm) Acumulado Após O Plantio (Dias) } & \multirow{2}{*}{ Médias } \\
\cline { 2 - 13 } & $\mathbf{6 0}$ & $\mathbf{1 2 0}$ & $\mathbf{1 8 0}$ & $\mathbf{2 4 0}$ & $\mathbf{3 0 0}$ & $\mathbf{3 6 0}$ & $\mathbf{4 2 0}$ & $\mathbf{4 8 0}$ & $\mathbf{5 4 0}$ & \\
\hline Crotalária & $0,25 \mathrm{~A}$ & $0,25 \mathrm{~A}$ & $0,38 \mathrm{~A}$ & $0,75 \mathrm{~A}$ & $1,00 \mathrm{~A}$ & $5,00 \mathrm{~A}$ & $6,50 \mathrm{~A}$ & $8,00 \mathrm{~A}$ & $9,50 \mathrm{~A}$ & 3,51 \\
\hline Feijão Guan. & $0,00 \mathrm{~A}$ & $0,00 \mathrm{~A}$ & $0,50 \mathrm{~A}$ & $0,75 \mathrm{~A}$ & $0,88 \mathrm{~A}$ & $1,25 \mathrm{~A}$ & $3,38 \mathrm{~A}$ & $5,88 \mathrm{~A}$ & $8,13 \mathrm{~A}$ & 2,31 \\
\hline Feijão Por. & $0,25 \mathrm{~A}$ & $0,25 \mathrm{~A}$ & $1,25 \mathrm{~A}$ & $1,00 \mathrm{~A}$ & $1,50 \mathrm{~A}$ & $1,63 \mathrm{~A}$ & $3,63 \mathrm{~A}$ & $5,25 \mathrm{~A}$ & $7,75 \mathrm{~A}$ & 2,50 \\
\hline Mucuna & $1,50 \mathrm{~A}$ & $1,50 \mathrm{~A}$ & $2,00 \mathrm{~A}$ & $2,13 \mathrm{~A}$ & $2,88 \mathrm{~A}$ & $2,88 \mathrm{~A}$ & $4,63 \mathrm{~A}$ & $6,88 \mathrm{~A}$ & $8,88 \mathrm{~A}$ & 3,69 \\
\hline Veg. Espon. & $0,38 \mathrm{~A}$ & $0,38 \mathrm{~A}$ & $1,13 \mathrm{~A}$ & $2,12 \mathrm{~A}$ & $2,38 \mathrm{~A}$ & $2,50 \mathrm{~A}$ & $3,50 \mathrm{~A}$ & $5,50 \mathrm{~A}$ & $6,38 \mathrm{~A}$ & 2,68 \\
\hline
\end{tabular}




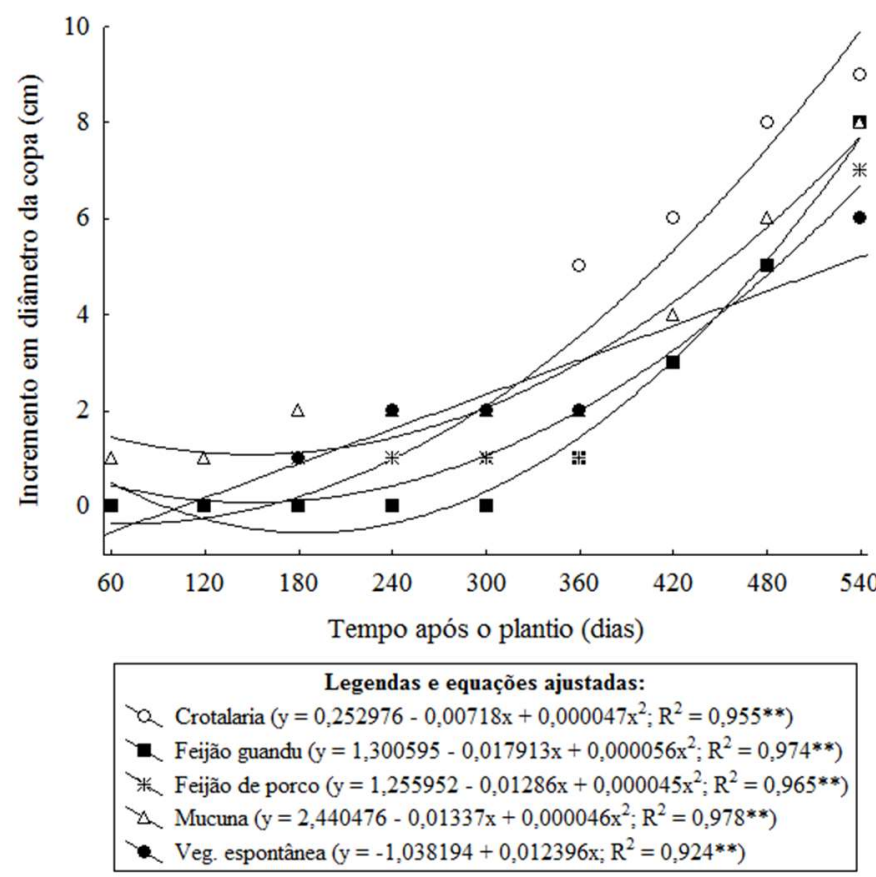

Figura 3: Análise de regressão para o diâmetro do caule de mudas de mangabeira (Hancornia speciosa) em diferentes épocas (dias) de avaliação e tipos de adubação verde. Ipameri/GO, 2018.

O sistema de desenvolvimento inicial e, estabelecimento de mudas em campo em consórcio com a adubação verde (crotalária, mucuna, vegetação espontânea, feijão de porco e gundu) pode proporcionar economia de adubação química. Nesse sistema, ao ofertar nutrientes que possam ser aos poucos incorporados pelas plantas via mineralização, é possível que esses adubos verdes, sejam capazes de atender parte da demanda das espécies frutíferas no decorrer do desenvolvimento das mudas de mangabeira. É interessante também que se realize, na área de plantio das mudas de frutíferas, nova adubação verde, pois com o passar do tempo, os adubos verdes tendem a perdas de nutrientes.

\section{DISCUSSÃO}

Segundo Beltrame et al. (2008) comparando diferentes densidades de feijão gandu na restauração florestal, observaram que a consorciação de árvores nativas com feijão guandu proporcionou efeitos positivos em alguns momentos para algumas espécies florestais e negativos em outros momentos para outras espécies.

Quando se comparam os resultados das adubações verdes deste estudo, infere-se que esse aporte pode ser o responsável pelo incremento observado para o desenvolvimento das mudas de mangabeira em consórcio com a citada leguminosa. Esses resultados concordam com Neto et al. (2010) que estudando o efeito da adubação orgânica e verde sobre o desenvolvimento do mamoeiro não observaram efeito significativo para diâmetro de caule utilizando feijão de porco e guandu aos 90 dias após o plantio.

A crotalária apresentou inicialmente as menores médias de incremento de altura $(\mathrm{cm})$ na mangabeira. Na avaliação após 540 dias, este adubo apresentou uma altura de 11,75 cm diferindo da maior média apresentada pelo feijão gandu com $18 \mathrm{~cm}$ de altura, seguido do feijão de porco e mucuna com $14 \mathrm{~cm}$. Por esses dados constata-se 11,76; 17,00;13,25; 13,00; 8,25 cm de incremento quanto aos adubos verdes, 
Crotálaria, Feijão-guando, Feijão de porco, Mucuna e Vegetação espontânea, respectivamente, em consórcio com a mangabeira em um período de 480 dias. Quando se avalia o Feijão-guandu com a vegetação espontânea, a amplitude gerada é $8,75 \mathrm{~cm}$ no decorrer do período de avaliação. As mudas de mangabeira quando instaladas em campo, podem apresentar crescimento de altura e diâmetro de caule com desenvolvimento variáveis em função dos genótipos e manejo (VIEIRA et al., 2012).

O fato da utilização do Feijão-guandu, como adubação pode ser uma alternativa para melhorar o desempenho das mudas no campo pois, esta leguminosa é uma planta que ao ser incorporada ao solo, permite a liberação rápida de nutriente e, por conseguinte, e incorporação desse material. Kitamura et al. (2008) em estudos com feijão de porco e Astronium fraxinifolium observaram valores médios de $30 \mathrm{~cm}$ na altura da espécie nas avaliações de 494 dias.

Para Paiva et al. (1993) o diâmetro da base do caule, pode ser um parâmetro crítico para estimar a sobrevivência de campo de mudas, em que o padrão de qualidade de mudas prontas para plantio tem uma alta correlação com o referido parâmetro, e que pode ser verificado por aumentos significativos nas taxas de sobrevivência e crescimento de plantas.

Em trabalho sobre o desenvolvimento de mudas de mangabeira no campo, Vieira et al. (2012), Observou que houve correlação entre a altura, o diâmetro e o número de par de folhas (NPF), indicando que quanto maior a planta, maior o diâmetro e o NPF. Esse fato pode sugerir que as plantas de mangabeira no campo, possam ter um desenvolvimento continuo, embora lento, fato também observado no presente estudo. Em estudo realizado com mangabeira (H. speciosa) Lima (2008), em Minas Gerais, observaram que plantas com 6 meses, possuíam em média 12,55 cm de altura, 0,27 cm de diâmetro. Pereira et al. (2010) em mudas produzidas em viveiro em que, as sementes foram oriundas de frutos de áreas naturais do Cerrado de Goiás, obtiveram uma média em altura de 10,95 cm aos 160 dias após a semeadura para essa espécie. No atual trabalho, constata-se que as mudas de mangabeira tiveram um incremento de 11,75 de $18 \mathrm{~cm}$ de altura quando estabelecidas no campo, se apresentando promissor nestas condições.

Segundo Vieira et al. (2010) e Paula et al. (2014) verificaram média final de crescimento de $3,75 \mathrm{~cm}$, para as mudas de mangabeira cultivadas em Goiânia, em 3 meses de avaliação. Já para as mudas plantadas em Urutaí/GO houve incremento com taxa média final de $0,5 \mathrm{~cm}$ de crescimento, no decorrer do mesmo período. É importante salientar que os dados do presente estudo, estão superiores quanto incremento no desenvolvimento das mudas de mangabeira, levando a constatar a importância da utilização da adubação verde no estabelecimento de mudas de mangabeira no campo. Segundo Vieira (2011), em estudos com produção de mudas de mangabeira de Goiás, a variabilidade é importante, especialmente quando se pretende identificar genótipos superiores para programas que visem o melhoramento de espécies. No entanto, fatores relacionados ao comportamento em campo de espécies não domesticadas, ainda carecem de estudos uma vez que tais espécies podem se comportar de formas variadas em resposta à diversidade de clima, solo, ação de herbívoros, bem como às adversidades que possam vir a ocorrer, e que muitas vezes, não podem ser controlados em plantas no campo. 


\section{CONCLUSÕES}

A mangabeira é uma frutífera nativa, que mostrou-se promissora quanto ao desenvolvimento de mudas em campo em consorcio com leguminosas, na região de Ipameri/GO. Nesse sentido é necessário salientar que: $\mathrm{O}$ incremento de altura final da mangabeira foi favorecido pelo feijão guandu. O consórcio com feijão de porco proporcionou maior incremento final de diâmetro do caule. O plantio de mudas de mangabeira (Hancornia speciosa) em consorcio com adubação verde se apresenta como promissor.

\section{REFERÊNCIAS}

BELTRAME, T. P.; RODRIGUES, E.. Comparação de diferentes densidades de feijão guandu (Cajanus cajan (L.) Millsp.) na restauração florestal de uma área de reserva legal no Pontal do Paranapanema, SP. Sci. For., Piracicaba, v.36, n.80, p.317327, 2008.

CARVALHO, M. A.; COSER, T. R.; REIN, T. A.; DANTAS, R. R.; SILVA, R. R.; SOUZA, K. W.. Manejo de plantas de cobertura na floração e na maturação fisiológica e seu efeito na produtividade do milho. Pesq. Agropec. Bras., Brasília, v.50, n.7, p.551-561, 2015.

EMBRAPA. Centro Nacional de Pesquisa de Solos. Sistema Brasileiro de Classificação de Solos. 2 ed. Rio de Janeiro: Embrapa Solos, 2006.

EMBRAPA AGROBIOLOGIA. Adubação verde. Utilização de leguminosas contribui no fornecimento de nitrogênio para culturas de interesse comercial e protege solo da erosão. 2011.

FERREIRA, D. F.. Estatística multivariada. Lavras: Ufla, 2008.

KITAMURA, A. E.; ALVES, M. C.; SUZUKI, L. G. A. S.; GONZALES, A. P.. Recuperação de um solo degradado com aplicação de adubos verdes e lodo de esgoto. Rev. Bras. de Ciências do Solo, n.32, p.405-416, 2008.

LEDERMAN, I. E.; SILVA Jr., J. F.; BEZERRA, J. E. F.; ESPÍNDOLA, A. C. M.. Mangabeira (Hancornia speciosa, Gomes). Jaboticabal: FUNEP, 2000.

LIMA, I. L. P.. Etnobotânica quantitativa de espécies do Cerrado e extrativismo de mangabeira ( $H$. speciosa Gomes) no Norte de Minas Gerais: Implicações para o manejo sustentável. Dissertação (Mestrado em Ecologia) Universidade de Brasília, 2008.

MAFRA, A. L.; MIKLOS, A. A. W.; VOCURCA, H. L.; HARKALY, A. H.; MENDONZA, E.. Produção de fitomassa e atributos químicos do solo sob cultivo em aléias e sob vegetação nativa de cerrado. Revista Brasileira de Ciência do Solo, Viçosa, n.22, p.41-54, 1998.

MACÊDO, M. H.. Conjuntura mensal: Mangabeira. CONAB, 2011.

MACHADO, L. L.; RAMOS, M. L. G.; CALDAS, L. S.; VIVALDI, L. J.. Seleção de matrizes e clones de mangabeira para o cultivo in vitro. Pesq. agropec. bras., Brasília, v.39, n.5, p.431-435, 2004.
NETO, J. F. B.; PEREIRA, W. E.; CAVALCANTI, L. F.; ARAÚJO, R. C; SOARES, W. B. S. S.; LACERDA, J. S.. Efeito da adubação orgânica e verde sobre o desenvolvimento do mamoeiro e as características químicas do solo. Engenharia Ambiental, Espirito Santo do Pinhal, v.7, n.1, p.159-168, 2010.

NETO, R. D. V.; CINTRA, F. L. D.; LEDO, A. S.; JÚNIOR, J.F.S.; COSTA, J. L. S.; SILVA, A. A. G.; CUENCA, M. A. G.. Sistema de produção de mangabeira para os tabuleiros costeiros e baixadas litorâneas. Embrapa, 2002.

PAIVA, H. N.; GOMES, J. M.. Viveiros florestais. Viçosa: UFV, 1993.

PAULA, L. C.; VIEIRA, M. C.; NAVES, R. V.; SOUZA, E. R. B.; MOZENA, W. L.. avaliação de mudas de mangabeira em condições de campo em Goiânia/GO. In: CONGRESSO BRASILEIRO DE FRUTICULTURA-OPORTUNIDADES E DESAFIOS PARA O BRASIL, 23. Anais. 2014.

PEREIRA, K. C.; VIEIRA, M. C.; AQUINO, A. S. M.; SILVA, L. B.; PADOVANNI, G. A. M.; GADELHA, D. B. G.. Avaliação da germinação e crescimento inicial da mangabeira em diferentes substratos. In: CONGRESSO BRASILEIRO DE FRUTICULTURA, 21. Anais. Natal: Sociedade Brasileira de Fruticultura, 2010.

SILVA JUNIOR, J. F.. A cultura da mangabeira. Revista Brasileira de Fruticultura, v.26, n.1, p.1-192, 2004.

VIEIRA NETO, R. D.. Mangabeira (Hancornia speciosa Gomes). In: SIMPÓSIO NACIONAL DE RECURSOS GENÉTICOS DE FRUTEIRAS NATIVAS. Anais. Cruz das Almas: Embrapa/CNPMF, 1993. p.109-116.

PAIVA, H. N.; GOMES, J. M.. Viveiros florestais. Viçosa: UFV, 1993.

VIEIRA, M. C.; SOUZA, E. R. B.; NAVES, R. V.; SELEGUINI, A.; BELO, A. P. M.; PEIXOTO, F. G. T.. Avaliação em campo do Desenvolvimento de mudas de mangabeira (Hancornia speciosa Gomes) de diferentes áreas do Cerrado do Estado de Goiás. In: CONGRESSO BRASILEIRO DE FRUTICULTURA; INST.PROMOTORA/FINANCIADORA: SOCIEDADE BRASILEIRA DE FRUTICULTURA, 22. Anais. Bento Gonçalves, 2012.

VIEIRA, M. C.; MARTINS, M. L.; BELO, A. P. M.; AFIUNECOSTA, L. V.; SOUZA, E. R. B.; SELEGUINI, A.; NAVES, R. V.. Avaliação da Germinação e Crescimento Inicial de Mangabeira de Diferentes Populações no Estado de Goiás. In: CONGRESSO BRASILEIRO DE FRUTICULTURA; SOCIEDADE BRASILEIRA DE FRUTICULTURA, 21. Anais. Natal, 2010. 
VIEIRA, M. C.. Caracterização de frutos e de mudas de mangabeira (Hancornia speciosa Gomes) de Goiás.
Monografia (Graduação em Agronomia) - Universidade Federal de Goiás, Goiânia, 2011.

A CBPC - Companhia Brasileira de Produção Científica (CNPJ: 11.221.422/0001-03) detém os direitos materiais desta publicação. Os direitos referem-se à publicação do trabalho em qualquer parte do mundo, incluindo os direitos às renovações, expansões e disseminações da contribuição, bem como outros direitos subsidiários. Todos os trabalhos publicados eletronicamente poderão posteriormente ser publicados em coletâneas impressas sob coordenação da Sustenere Publishing, da Companhia Brasileira de Produção Científica e seus parceiros autorizados. Os (as) autores (as) preservam os direitos autorais, mas não têm permissão para a publicação da contribuição em outro meio, impresso ou digital, em português ou em tradução. 